\title{
Regulamentação da propaganda de alimentos infantis como estratégia para a promoção da saúde
}

\author{
Regulation of publicity for children's food \\ as a strategy for promotion of health
}

Patrícia Henriques ${ }^{1}$

Enilce Oliveira Sally ${ }^{1}$

Luciene Burlandy ${ }^{1}$

Renata Mondino Beiler ${ }^{1}$
${ }^{1}$ Faculdade de Nutrição Emilia de Jesus Ferreiro, Universidade

Federal Fluminense. Rua Mario Santos Braga 30

Campus do Valonguinho,

Centro. 24020-140

Niteroi RJ.

patriciah@uol.com.br

\begin{abstract}
The eating habits of the Brazilian population have been changing in recent decades and publicity is one of the factors contributing to this situation. The objective of this study was to evaluate the content of food publicity broadcast on television and addressed to children, from the standpoint of regulation. The publicity broadcast on the two major television stations during the school holidays was recorded on VHS tapes. Content analysis techniques were used and eight categories of analysis were defined based on the theoretical benchmark of the eating habits and their determining factors. The proposal for a Technical Regulation of Anvisa was used to conduct this analysis. 1018 advertisements were recorded, of which $132(12.9 \%)$ that advertised foods targeted at children were selected, but only 12 different products were identified. According to the proposed regulation, all the material analyzed violated no less than three articles, among which the 4th, Sections III and VIb stand out. The pressing need for government regulation of the content of food advertisements for children, the consumption of which can be harmful to health, is clearly apparent because of its influence on the decision to purchase, both by the children themselves, and their parents.
\end{abstract}

Key words Food publicity, Television, Children
Resumo As práticas alimentares da população brasileira vêm se alterando nas últimas décadas e a publicidade é um dos fatores que contribuem para esta situação. O objetivo deste trabalho foi avaliar o conteúdo das propagandas de alimentos veiculadas na televisão e dirigidas a crianças, sob a ótica da regulação. As propagandas foram gravadas em fitas VHS de duas grandes emissoras de televisão, no período de férias escolares. Foram utilizadas técnicas de análise de conteúdo e definidas oito categorias de análise a partir do referencial teórico sobre as práticas alimentares e seus determinantes. Para subsidiar a análise utilizouse a proposta de Regulamento Técnico da Anvisa. Foram contabilizadas 1018 propagandas, das quais foram selecionadas as 132 (12,9\%) que anunciavam alimentos dirigidos para as crianças, sendo identificados somente 12 produtos diferentes. De acordo com o Regulamento proposto, todas as propagandas analisadas infringiam pelo menos três artigos, entre os quais se destaca o $4^{\circ}$, Incisos III $e$ VIb. É nítida a urgência do setor público de regular o conteúdo das propagandas de alimentos infantis, cujo consumo pode ser prejudicial à saúde devido à influência que exercem na decisão pela compra, tanto por parte das próprias crianças, quanto dos pais.

Palavras-chave Propaganda de alimentos, Televisão, Público infantil 


\section{Introdução}

As práticas alimentares da população brasileira vêm se alterando nas últimas décadas, em virtude principalmente das transformações no cotidiano de vida e de trabalho decorrentes de múltiplos fatores que marcam a contemporaneidade, tais como: a urbanização; as mudanças na relação entre tempo e espaço, a industrialização crescente, a multiplicidade de atribuições da mulher, que ainda exerce papel central no cuidado com a saúde e a alimentação da família, o marketing, dentre outros. Estes fatores contribuem para reforçar o consumo de alimentos industrializados, a realização de refeições fora do domicílio (em cantinas, restaurantes, fast food), bem como a busca pela praticidade e economia de tempo. Se, por um lado, as práticas alimentares se adéquam ao ritmo acelerado do cotidiano, por outro, a indústria de alimentos capitaliza esta problemática oferecendo "soluções" para reduzir o tempo de preparo através dos alimentos pré-cozidos, congelados, enlatados, etc. ${ }^{1-4}$.

As crianças têm sido expostas cada vez mais cedo a esse tipo de alimentação seja pelo aumento da jornada de trabalho dos pais, ou pela falta de opções saudáveis nas escolas ou ainda pelo bombardeio de propagandas de produtos alimentícios que influenciam negativamente suas escolhas alimentares. Neste sentido, Rubim ${ }^{5}$ afirma que os meios de comunicação cada vez mais estruturam a sociedade em função do crescente papel que desempenham no modo pelo qual as pessoas percebem a realidade, a exemplo do número de horas que ocupam no cotidiano, e da abrangência das culturas midiáticas como circuito cultural que organiza e difunde socialmente comportamentos, percepções, sentimentos, ideários e valores.

Considerada o "quarto poder", a mídia assume funções de difusora e de operadora de sentidos e de reafirmação de valores da sociedade globalizada ${ }^{6}$. Estudos têm destacado a associação essencial das mídias com o desenvolvimento capitalista e sua difusão na consolidação da sociedade de consumo. Segundo Sodré e Moraes ${ }^{7}, a$ forma de poder típica da mídia hoje, é a forma persuasiva, do convencimento, e da sedução.

A televisão, dentre todas as mídias veiculadoras de publicidade, é a mais significativa ${ }^{8}$. Seu grande poder impactante sobre o consumidor no nível coletivo decorre do uso de três elementos básicos na transmissão de mensagens: o som, a imagem e o movimento, captando a atenção do espectador com mais facilidade e adesão ${ }^{9}$. É a mídia mais popular, presente em $98 \%$ das residências brasileiras e preferida por $88 \%$ das crianças que passaram a ocupar, desde as décadas de 70 e 80 , o lugar de espectadoras/consumidoras do mercado publicitário ${ }^{10}$.

As crianças interagem com a televisão, muitas vezes, como se fosse seu semelhante. Através desse meio de comunicação, entretanto, elas podem adquirir uma concepção inadequada do que seja um alimento saudável ${ }^{11}$.

Estudos indicam que as crianças brasileiras estão gastando mais tempo em frente à televisão do que praticando atividade física ${ }^{12,13}$. Além de ser uma atividade na qual não se tem dispêndio de energia, alguns pesquisadores sugerem que a programação assistida influencia na formação de hábitos alimentares, contribuindo para o aumento da incidência de sobrepeso e obesidade nesta faixa etária ${ }^{14,15}$.

Para Engesveen ${ }^{16}$, as crianças representam uma oportunidade bem explorada pelos profissionais de comunicação e marketing para alcançar toda a família, devido ao seu considerável "poder de importunação". Na sociedade de consumo, passaram a ser consideradas como clientes em função da crescente influência sobre as decisões de compra da família.

Atualmente, a propaganda de alimentos tem sido foco de discussões entre especialistas da área de saúde, uma vez que existem fortes evidências de que a mídia televisiva influencia as preferências alimentares da sociedade. Acredita-se que tais propagandas vêm contribuindo para um "ambiente obesogênico", valorizando os alimentos altamente calóricos e pouco nutritivos, dificultando escolhas mais saudáveis ${ }^{17}$.

Desta forma, a regulamentação da propaganda de certos produtos que, se consumidos em excesso, podem ser prejudiciais à saúde, poderia encorajar melhores escolhas na alimentação, possibilitando um melhor controle das pessoas sobre comportamentos inadequados à sua saúde ${ }^{17}$.

Neste sentido, o governo brasileiro formulou uma proposta de Regulamento Técnico que normatiza os termos das atividades publicitárias destinadas ao público infantil ${ }^{18}$ ratificada pela Resolução no 408/2008 do Conselho Nacional de Saúde, que também estabelece diretrizes para a promoção da alimentação saudável com impacto na reversão da epidemia de obesidade e prevenção das doenças crônicas não transmissíveis ${ }^{19}$.

Este Regulamento Técnico trata da oferta, propaganda, publicidade, informações e outras práticas correlatas, cujo objeto seja a divulgação ou a promoção de alimentos com quantidade 
elevada de açúcar, gordura trans, sódio e de bebidas de baixo teor nutricional. Em seus termos, propaganda e publicidade possuem o mesmo significado, abrangendo um conjunto de técnicas e atividades de informação e persuasão, com fins ideológicos ou comerciais, utilizadas com o objetivo de divulgar conhecimento e/ou visando exercer influência sobre o público, por meio de ações que visem promover e/ou induzir a prescrição, a aquisição, a utilização e o consumo de alimentos ${ }^{18}$. Assim, considerando o aumento do sobrepeso e da obesidade ${ }^{20}$ e a possível influência que a televisão possui em suas escolhas alimentares, este trabalho teve como objetivo analisar as propagandas de alimentos dirigidas às crianças, veiculadas em dois canais de televisão, caracterizando seus argumentos e a conformidade com a legislação que está sendo proposta.

\section{Métodos}

O estudo foi realizado no mês de julho de 2008, por meio de gravações da programação de duas principais emissoras de televisão de canal aberto no país tratadas como A e B. A escolha pelo mês de julho ocorreu por ser este um período de férias escolares. Foi estabelecido um período de oito dias de estudo para cada emissora.

A coleta do material anunciado foi realizada em fitas de vídeo VHS em dois períodos do dia (das $9 \mathrm{~h}$ às $12 \mathrm{~h}$ e das $16 \mathrm{~h}$ às $18 \mathrm{~h}$ ) entre as segundas e sextas feiras e no sábado, somente no período da manhã (das $8 \mathrm{~h}$ às $12 \mathrm{~h}$ ), de modo a abranger toda a programação infantil, incluindo os anúncios comerciais durante os intervalos dos programas.

As propagandas foram quantificadas e descritas, por dia de gravação, e transcritas na íntegra para identificação do conteúdo. O conceito de propaganda adotado baseou-se em Fontene$1 \mathrm{e}^{21}$, qual seja o anúncio comercial pago disseminado através de um veículo de comunicação de massa.

Foram utilizadas técnicas de análise de conteúdo que possibilitam um tratamento qualitativo e quantitativo de diversos tipos de materiais linguísticos, incluindo produtos da mídia ${ }^{22-24}$. Foram definidas oito categorias de análise a partir do referencial teórico sobre as práticas alimentares e seus determinantes, reiteradas com base no material empírico (propagandas e legislação). Este referencial fundamenta tanto os termos da legislação estudada, quanto as estratégias de marketing utilizadas pela indústria de alimentos no conjunto de propagandas analisado. A partir destas categorias, as mensagens de comunicação das propagandas foram classificadas segundo semelhanças e diferenciações e agrupadas em função de princípios comuns, a saber: o produto é essencial para saúde; o produto substitui alimentos naturais; o produto é benéfico para saúde; o produto pode substituir uma refeição; persuasão da criança sobre os pais; uso de personagens, personalidades, desenhos e figuras; estímulo ao consumo excessivo; e, aquisição de brindes.

Para análise das propagandas selecionou-se os cinco artigos do regulamento proposto na Consulta Pública $n^{0} 71 / 06^{18}$, mais relacionados com a temática do estudo:

Artigo 4\%: Relaciona-se aos alimentos com quantidade elevada de açúcar, de gorduras, de sódio e de bebidas com baixo teor nutricional.

Inciso III - alertas sobre o consumo excessivo dos nutrientes por meio de mensagem

Inciso IV - quando o alimento possuir quantidade elevada de dois ou mais nutrientes alertar conjuntamente

Inciso V - veiculação de mensagens para conjunto de produtos com natureza diferente, quando pelo menos um alimento se enquadrar na classificação em questão.

Inciso VIb - especifica formatação e exibição da mensagem em relação a legibilidade, visibilidade, audibilidade.

Artigo $5^{\circ}$

Inciso II - vedado sugerir que o alimento garanta saúde.

Inciso VII - vedado sugerir que substitua alimentos naturais.

Inciso VIII - vedado encorajar o consumo de alimentos com quantidade elevadas de açúcar, gorduras e sódio e bebidas com baixo teor nutricional.

Inciso IX - vedado sugerir que este tipo de alimento é saudável.

Inciso X - vedado sugerir que o alimento possa substituir refeição.

Inciso XIII - encorajar crianças a persuadir os pais e outros a adquirir ou consumir estes alimentos.

Artigo $6^{\circ}$ - vedado utilizar figuras, desenhos, personalidades e personagens admirados pelas crianças.

Artigo 7o - define o horário de veiculação das propagandas.

Artigo $9^{\circ}$ - vedada divulgação de brindes, prêmios, bonificações e apresentações especiais.

Por questões éticas os nomes dos produtos e das marcas comerciais foram substituídos no 
texto, pelo nome do alimento e aqueles que apresentaram mais de uma marca comercial foram descritos com números sobrescritos.

Para classificar os produtos quanto à quantidade de sal, açúcar e gorduras foi realizada uma análise da rotulagem nutricional tendo como parâmetros as definições que constam na proposta do Regulamento Técnico.

\section{Resultados}

O registro de 16 dias de programação representou um total de 1018 propagandas, das quais foram selecionadas as $132(12,9 \%)$ que anunciavam produtos alimentícios dirigidos para o público infantil. Desta quantidade, foram identificados somente 12 produtos anunciados, dos quais cinco foram transmitidos pela emissora A, quatro pela $B$ e três foram anunciados em ambas emissoras. Esse pequeno número reflete a exposição maciça dos produtos, independentemente do horário ou do dia da semana. O Quadro 1 apresenta os produtos anunciados por emissora de TV, os argumentos utilizados e as não conformidades aos artigos e seus respectivos incisos do Regulamento Técnico.

Na Tabela 1 pode-se observar a distribuição de artigos e incisos que não estariam sendo cumpridos, caso o regulamento estivesse em vigor. Levando em consideração o artigo $4^{\circ}$ da Consulta Pública, verifica-se que quase todas as propagandas $(91,6 \%)$ estariam em desacordo com ambos os incisos III e VI.b, os quais estão diretamente interrelacionados. O inciso III se refere à mensagem de alerta sobre os perigos do consumo excessivo de açúcar, gordura saturada, gordura trans e sódio, que deveria aparecer após a propaganda dos produtos ricos em tais nutrientes nocivos à saúde. Já o VI.b, refere-se às regras de apresentação da mensagem de alerta, que no caso da televisão, esta deveria ser exibida de forma a permitir a perfeita legibilidade, visibilidade, além de ser perfeitamente audível.

Além destes, 58,3\% das propagandas infringiram o inciso IV por não alertarem conjuntamente que o produto excede os limites previstos em relação a dois ou mais nutrientes sob os quais incide a regulamentação. Por outro lado, somente $25 \%$ não atenderam ao inciso $\mathrm{V}$, que se refere à apresentação da mensagem de alerta vinculada à propaganda de um conjunto de produtos de natureza diferente, quando pelo menos um deles apresentar qualquer um daqueles nutrientes em excesso.
Com relação ao artigo $5^{\circ}$ do regulamento proposto, $25 \%$ das propagandas estariam em desacordo com o inciso II por informar ou sugerir que o consumo do produto garantia boa condição de saúde, utilizando expressões que o caracterizava como fundamental para o adequado crescimento e desenvolvimento da criança. Da mesma forma, $25 \%$ não obedeceram ao inciso VII ao informar ou sugerir que o produto possuía nutriente ou fibras alimentares, adicionados intencionalmente, podendo substituir as fontes alimentares naturais. Além disso, 50\% das propagandas estimulavam o consumo excessivo do produto comercializado, estando, portanto, em desacordo com o inciso VIII.

Metade das propagandas não obedeceu ao inciso IX, por sugerir que o produto era saudável ou benéfico à saúde, porque associara seu consumo a outros alimentos considerados saudáveis ou à prática de atividades esportivas como estratégia para chamar a atenção do telespectador. Em relação ao inciso X, $41 \%$ das propagandas estavam em desacordo, uma vez que sugeriam que o alimento poderia substituir uma refeição. Em contrapartida, apenas 16,6\% infringiram ao inciso XIII, ao encorajar direta ou indiretamente as crianças a persuadirem seus pais para adquirir ou consumir o produto.

Verificou-se que $69,2 \%$ das propagandas estariam em desacordo com o artigo $6^{\circ}$, que veda a utilização de figuras, desenhos, personalidades e personagens que sejam cativos ao público infantil, associados à propaganda de produtos com elevados teores de açúcar, gordura saturada, gordura trans ou sódio, e bebidas de baixo teor nutricional. Além disso, todas as propagandas infringiram o artigo $7^{\circ}$ que restringe $o$ horário permitido para divulgação desses produtos.

Por fim, quase metade das propagandas $(46,1 \%)$ oferecia brindes associados à aquisição dos produtos comercializados, infringindo o artigo $9^{\circ}$. Vale destacar, entretanto, que apesar do brinde associado, verificou-se positivamente que em uma das propagandas analisadas apareciam legumes e verduras, além da típica mistura do arroz com feijão, oferecendo assim uma opção mais saudável para uma refeição infantil realizada fora de casa.

\section{Discussão}

A infância e a adolescência são fases marcadas pelo processo de formação dos valores mais importantes da vida, inclusive em relação à perso- 
Quadro 1. Produtos alimentícios anunciados por emissora de TV, segundo os argumentos utilizados e as não conformidades com o Regulamento Técnico proposto.

\begin{tabular}{|c|c|c|c|}
\hline Emissoras de TV & Produto & Argumentos & Não conformidades \\
\hline \multirow{5}{*}{ A } & Leite acidificado & $\begin{array}{l}\text { O produto é essencial para saúde } \\
\text { O produto substitui alimentos naturais } \\
\text { O produto é benéfico para saúde } \\
\text { Persuasão da criança sobre os pais } \\
\text { Uso de personagens }\end{array}$ & $\begin{array}{l}\text { Art. } 5^{\circ} \text { II } \\
\text { Art. } 5^{\circ} \text { VII } \\
\text { Art. } 5^{\circ} \text { IX } \\
\text { Art. } 5^{\circ} \text { XIII } \\
\text { Art. } 6^{\circ}\end{array}$ \\
\hline & Fast food ${ }^{1}$ & $\begin{array}{l}\text { Estímulo ao consumo excessivo } \\
\text { O produto pode substituir uma refeição } \\
\text { Uso de personagens } \\
\text { Aquisição de brindes }\end{array}$ & $\begin{array}{l}\text { Art. } 5^{\circ} \text { VIII } \\
\text { Art. } 5^{\circ} \mathrm{X} \\
\text { Art. } 6^{\circ} \\
\text { Art. } 9^{\circ}\end{array}$ \\
\hline & Cereal matinal $^{1}$ & $\begin{array}{l}\text { O produto substitui alimentos naturais } \\
\text { O produto é benéfico para saúde } \\
\text { O produto pode substituir uma refeição }\end{array}$ & $\begin{array}{l}\text { Art. } 5^{\circ} \mathrm{VII} \\
\text { Art. } 5^{\circ} \mathrm{IX} \\
\text { Art. } 5^{\circ} \mathrm{X}\end{array}$ \\
\hline & Chocolate & $\begin{array}{l}\text { O produto é essencial para saúde } \\
\text { O produto substitui alimentos naturais } \\
\text { O produto é benéfico para saúde } \\
\text { Persuasão da criança sobre os pais } \\
\text { Aquisição de brindes }\end{array}$ & $\begin{array}{l}\text { Art. } 5^{\circ} \mathrm{II} \\
\text { Art. } 5^{\circ} \mathrm{VII} \\
\text { Art. } 5^{\circ} \mathrm{IX} \\
\text { Art. } 5^{\circ} \mathrm{XIII} \\
\text { Art. } 9^{\circ}\end{array}$ \\
\hline & Fast food ${ }^{2}$ & $\begin{array}{l}\text { Estímulo ao consumo excessivo } \\
\text { O produto é benéfico para saúde } \\
\text { O produto pode substituir uma refeição } \\
\text { Uso de figuras } \\
\text { Aquisição de brindes }\end{array}$ & $\begin{array}{l}\text { Art. } 5^{\circ} \mathrm{VIII} \\
\text { Art. } 5^{\circ} \mathrm{IX} \\
\text { Art. } 5^{\circ} \mathrm{X} \\
\text { Art. } 6^{\circ} \\
\text { Art. } 9^{\circ}\end{array}$ \\
\hline \multirow{4}{*}{ B } & Salgadinho tipo snack ${ }^{1}$ & Estímulo ao consumo excessivo & Art. $5^{\circ}$ VIII \\
\hline & Salgadinho tipo snack ${ }^{2}$ & $\begin{array}{l}\text { Estímulo ao consumo excessivo } \\
\text { Uso de figuras } \\
\text { Aquisição de brindes }\end{array}$ & $\begin{array}{l}\text { Art. } 5^{\circ} \text { VIII } \\
\text { Art. } 6^{\circ} \\
\text { Art. } 9^{\circ}\end{array}$ \\
\hline & Fast food ${ }^{3}$ & $\begin{array}{l}\text { Estímulo ao consumo excessivo } \\
\text { O produto pode substituir uma refeição } \\
\text { Uso de figuras } \\
\text { Aquisição de brindes }\end{array}$ & $\begin{array}{l}\text { Art. } 5^{\circ} \text { VIII } \\
\text { Art. } 5^{\circ} \mathrm{X} \\
\text { Art. } 6^{\circ} \\
\text { Art. } 9^{\circ}\end{array}$ \\
\hline & Chiclete & Uso de personagem & Art. $6^{\circ}$ \\
\hline \multirow[b]{3}{*}{$\mathrm{A}$ e B } & Creme de avelã e cacau & $\begin{array}{l}\text { O produto é benéfico para saúde } \\
\text { Uso de personagem }\end{array}$ & $\begin{array}{l}\text { Art. } 5^{\circ} \mathrm{IX} \\
\text { Art. } 6^{\circ}\end{array}$ \\
\hline & Biscoito recheado & Uso de personagem & Art. $6^{\circ}$ \\
\hline & Cereal matinal $^{2}$ & $\begin{array}{l}\text { O produto é essencial para saúde } \\
\text { Estímulo ao consumo excessivo } \\
\text { O produto é benéfico para saúde } \\
\text { Substituição de refeição } \\
\text { Uso de Personagem } \\
\text { Aquisição de brinde }\end{array}$ & $\begin{array}{l}\text { Art. } 5^{\circ} \mathrm{II} \\
\text { Art. } 5^{\circ} \mathrm{VIII} \\
\text { Art. } 5^{\circ} \mathrm{IX} \\
\text { Art. } 5^{\circ} \mathrm{X} \\
\text { Art. } 6^{\circ} \\
\text { Art. } 9^{\circ}\end{array}$ \\
\hline
\end{tabular}

${ }^{1,2,3}$ : Marcas comerciais diferentes 


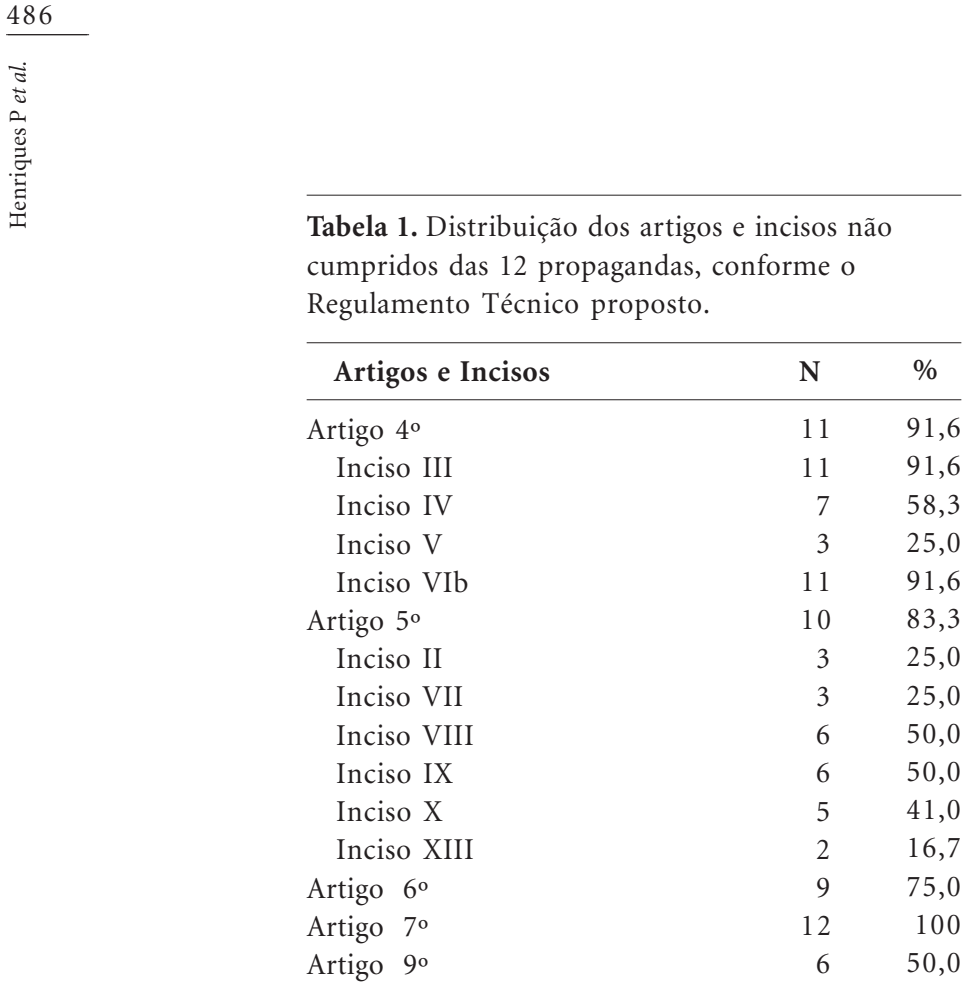

nalidade e à alimentação. Esta ocupa um lugar central na estruturação das relações sociais, seja em família ou nos diferentes grupos e espaços onde as crianças e adolescentes convivem. Ela é um veículo de expressão de afeto e também de valores nas relações entre pais e filhos, podendo ser por vezes uma forma de compensação emocional, um mecanismo de recompensa por méritos, de manipulação, de chantagem e também de formação de identidade social, de compartilhar gostos e de familiaridade. Por esse motivo, a nutrição nesta época da vida é essencial para garantir um processo adequado de crescimento e desenvolvimento. Hábitos alimentares adquiridos nessa etapa geralmente são levados para a fase adulta, condicionando o estado nutricional e podendo contribuir para o desenvolvimento de doenças relacionadas às práticas alimentares. Portanto, a forma como os valores sobre a alimentação são disseminados na sociedade, considerando a importância crescente que a cultura midiática vem assumindo neste processo, deve ser tratada como uma questão de caráter público.

No presente estudo pôde-se observar que, durante a programação infantil, os produtos alimentícios voltados para este público foram divulgados na televisão de forma repetida e intensa, sendo a maioria deles com alta densidade energética, como é o caso dos cereais matinais, por conter excesso de açúcar, e dos salgadinhos tipo snacks e fast foods pelo elevado teor de gorduras, além do sódio. Considerando a composição nu- tricional informada na rotulagem, verificou-se que uma única porção continha a quantidade total daqueles nutrientes que uma criança poderia consumir ao longo de um $\mathrm{dia}^{25}$. Portanto, uma mensagem de alerta sobre o perigo do consumo excessivo desses alimentos deveria aparecer junto às propagandas, conforme prevê o inciso III do artigo $4^{\circ}$, o qual não foi cumprido por quase todas elas $(91,6 \%)$, ou seja, impediu que o consumidor conhecesse e avaliasse o risco ao decidir sobre o consumo.

Contrariando também o regulamento proposto, metade das propagandas estimulava o consumo excessivo dos alimentos anunciados. Destaca-se que três deles (creme de avelã e cacau, biscoito recheado e cereal matinal) foram anunciados nas emissoras A e B.

A presença predominante de propagandas de alimentos através da televisão, dentre os comerciais anunciados, foi observada no Brasil tanto por Almeida et al. ${ }^{11}$ quanto por Halpern ${ }^{26}$. Alguns estudos vêm sendo conduzidos com o objetivo de verificar a frequência de propaganda de alimentos, o tempo gasto em frente à TV e o consumo de alimentos por crianças e adolescentes. Um estudo realizado com escolares espanhóis identificou consumo excessivo de açúcar, guloseimas e refrescos associado ao elevado número de horas em frente à televisão ${ }^{27}$. Uma pesquisa realizada com adolescentes norte-americanos verificou que a exposição maciça à propaganda pela televisão influenciou negativamente suas escolhas alimentares em longo prazo $^{28}$. Pimenta e Palma ${ }^{29}$ constataram que a média de tempo semanal dedicada pelas crianças a assistir televisão foi quase 2,5 vezes maior do que a média de tempo gasto praticando atividade física. Santos ${ }^{30}$ verificou que o tempo em frente à TV foi superior a três horas diárias, segundo informação da maioria dos responsáveis pelas crianças pesquisadas.

A preferência infantil por guloseimas é amplamente reconhecida e sofre influência tanto ambiental, quanto genética ${ }^{31}$. No entanto, tais preferências estão cada vez mais divergentes das recomendações nutricionais. Fiates et al. ${ }^{31}$ verificaram que os alimentos do grupo de açucarados foram o segundo item mais comprado pelas crianças que recebiam mesadas.

Neste contexto, o atual quadro epidemiológico, marcado pelo aumento de excesso de peso, obesidade e doenças crônicas não transmissíveis, tem gerado discussões por todo o mundo, inclusive no Brasil, acerca do papel da televisão e do marketing no crescimento dessas enfermidades ${ }^{32}$. Embora ainda não haja provas contundentes de 
que o marketing de alimentos prejudiciais à saúde, por si só, possa contribuir para a obesidade e para as doenças não transmissíveis, não há qualquer dúvida de que ele afeta as escolhas das pessoas e, assim, os perfis de consumo ${ }^{16}$.

Frente à polêmica sobre crianças e adolescentes serem alvos de anúncios publicitários, alguns países da Europa já proibiram propagandas voltadas para este público ${ }^{33}$. Essa iniciativa se deve ao fato de que as crianças não possuem senso crítico para compreender totalmente o conteúdo das propagandas, tendo em vista as estratégias utilizadas pelos profissionais de marketing. Frequentemente elas confundem programa de televisão com a mensagem publicitária, fato que se agrava ainda mais quando são utilizados personagens nos produtos comercializados ${ }^{34}$.

A programação infantil se tornou praticamente um sinônimo de comércio, tendo em vista o reconhecimento dos profissionais de marketing acerca do poder e da capacidade do público infantil de influenciar nas decisões de compra de suas famílias ${ }^{33}$.

De acordo com Story e French ${ }^{35}$, o primeiro pedido por qualquer produto se dá por volta dos 2 anos de idade. Nesta fase, a criança associa as embalagens comercializadas às assistidas em propagandas da televisão ${ }^{15}$. Santos ${ }^{30}$ identificou que a faixa com maior incidência de solicitações do que é veiculado nas propagandas é a que compreende crianças entre 3 e 6 anos.

Neste estudo, algumas estratégias de marketing foram identificadas na veiculação dos produtos anunciados, dentre elas, a utilização de música, de brindes e de personagens, mascote das marcas divulgadas, cuja função é humanizar a marca e apelar pela afetividade da criança despertando seu carisma pelo produto. Destaca-se que o intervalo comercial apresenta volume sonoro mais alto que o restante da programação como forma de chamar a atenção do espectador. Levando em consideração a alta capacidade de aprendizagem do público infantil, a música é uma ótima estratégia para que a criança memorize a letra e faça associação da melodia com o produto, facilitando o pedido pelo mesmo. Do mesmo modo, a oferta de brindes possui grande potencial de persuasão, uma vez que a criança se sente recebendo alguma bonificação, um prêmio, ao consumir tal produto. Além disto, na maioria das vezes, os brindes são colecionáveis, estimulando um consumo maior e o desejo de inclusão das crianças num perfil socialmente compartilhado, ou seja, se os colegas e amigos possuem aquele produto, as crianças tendem a persuadir ainda mais os pais para adquiri-los. Soma-se a isto o fato de que, em geral, a população desconhece e os estabelecimentos de comercialização não divulgam a obrigatoriedade da venda não casada dos brindes que são comercializados ou distribuídos a um preço mais baixo, conjugados à compra de produtos alimentícios.

A alusão à saúde foi identificada como mais um apelo utilizado nas propagandas. Cada vez mais, informações acerca do valor nutritivo dos alimentos vêm sendo ressaltadas nas propagandas como forma de atrair a atenção do consumidor. Neste contexto, é importante destacar que a percepção do público sobre essas estratégias de marketing pode estar comprometida pela não identificação imediata dos mecanismos que são utilizados para persuadir a compra do produto. Além disto, deve-se considerar a sutileza de algumas destas estratégias que induzem e criam uma demanda de consumo que nem mesmo existia para o próprio consumidor, levando-o, enfim, a escolher o produto em função da imagem veiculada e não necessariamente de suas necessidades objetivas.

Assim, quanto menor for a clareza sobre as motivações que induzem à vontade de consumir, maiores são as chances de o indivíduo reagir inconscientemente, impulsionado pelos efeitos das imagens e das ideias vinculadas ao produto ${ }^{36}$.

As propagandas não só associam o consumo de seu produto diretamente a uma série de imagens agradáveis, tornando a mensagem alegre, bonita ou engraçada, mas o correlacionam à criação de memórias afetivas positivas, que funcionam como estímulos inconscientes, levando as pessoas a decidirem pelo consumo, sendo essa, uma das razões pelas quais as propagandas são bem sucedidas ${ }^{37}$.

A exposição à propaganda deflagra no indivíduo um processo no qual o produto anunciado passa a ter dupla existência: como uma mercadoria, passível de ser substituída por outra qualquer e, como um bem provido de significados e subjetividade, sobretudo, pelo seu valor simbólico, desconectado da sua relação com o concreto, capaz de transformar a pessoa que o consome $^{36}$. No caso da alimentação, uma área da vida humana que integra o processo de construção das relações em sociedade, as estratégias de marketing incidem sobre os valores e as práticas sociais vigentes tentando conduzir ao consumo de produtos específicos.

Desta forma, mecanismos de proteção devem ser garantidos pelo Estado para que coíbam as estratégias que atuam sobre os aspectos subjetivos 
das práticas sociais e de valores sociais que inclusive afetam as relações sociais, como a própria relação das crianças com os pais. Nesse sentido, é importante que a criança seja protegida, ao longo da sua vida, desse ambiente de estímulos voltados para o consumo, de modo a não interferir negativamente, na fase adulta, na sua capacidade crítica e em sua autonomia nas decisões.

Ademais, considerando que o Brasil estabeleceu através da Lei Orgânica de Segurança Alimentar o princípio do Direito Humano à alimentação adequada faz-se necessário que ações no sentido de proteção e promoção à saúde sejam garantidas, principalmente por parte do Estado, que tem a obrigação de respeitar, proteger e fazer cumprir este direito ${ }^{38}$.

Os instrumentos de governo que promovem uma regulação pública de práticas sociais são considerados medidas de proteção, pois estabelecem limites em torno dos riscos em saúde advindos da ação de terceiros; no caso em questão a própria indústria e seus instrumentos de marketing. A ação pública não deve se restringir a limitar a publicidade dos alimentos não saudáveis, mas opções alimentares saudáveis precisam ser simultaneamente incentivadas, apoiadas e protegidas $^{39}$.

Em relação à regulamentação técnica em pauta, os limites estabelecidos para as propagandas incidem sobre a forma como a indústria explora em seu favor os fatores que condicionam as práticas alimentares no cotidiano das crianças e das mães. Ou seja, no caso das crianças, a indústria realça o sabor dos alimentos processados através do alto teor de açúcares e gorduras, considerando o atrativo do paladar doce e gorduroso. Além disto, promove a associação com personagens que fazem parte de seu imaginário social criando uma relação de confiança e afetividade com o produto, dois elementos que são essenciais na infância. No caso das mães, explora a praticidade aliada também à confiança de que aquele produto supre as necessidades alimentares da criança, quando o mesmo é enriquecido com vitaminas e minerais. Assim, se por um lado, a dinâmica cotidiana de vida favorece a demanda por produtos práticos e de rápido preparo e consumo, por outro há também uma preocupação social com a saúde diante dos múltiplos riscos das práticas alimentares contemporâneas associadas às doenças crônicas não transmissíveis, seja pelo baixo consumo de frutas, legumes e verduras e consequentemente de micronutrientes, ou pelo consumo excessivo de açúcar, sódio e gorduras. A indústria, por sua vez, capita- neia todos estes elementos apresentando saídas que aparentemente "respondem" a estas demandas e consequentemente estimulam a venda de seus produtos.

Neste caso, o Regulamento Técnico proposto próbe nos incisos do artigo $5^{\circ}$ que as mensagens veiculadas nas propagandas sugiram que alimentos com conteúdo elevado de açúcar, gordura e sódio possam garantir saúde ou serem substitutivos de alimentos naturais ou mesmo estarem associados a estes alimentos.

Além disso, o Regulamento proíbe uma série de práticas publicitárias que podem incidir sobre fatores subjetivos que afetam a alimentação como os aspectos psico-sociais, a autoestima, os vínculos sociais, as concepções em torno do próprio corpo e da imagem pessoal e também as relações sociais, especialmente no âmbito familiar.

Uma vez que a alimentação constituiu também uma forma de cuidado dos pais e dos educadores em relação à criança, quando a propaganda explora esta dimensão de forma deturpada os riscos residem não só nos aspectos de saúde, considerando a composição nutricional dos produtos, mas de forma ainda mais ampla e perigosa, nos valores em torno da identidade pessoal e das relações sociais mais caras à criança, quais sejam com os pais e com os educadores.

Adicionalmente, quando a propaganda associa produtos com profissionais que dão legitimidade àquele consumo, especialmente profissionais de saúde, ela está potencializando a relação de confiança das crianças para com os adultos que cuidam dela e dos adultos em relação aos profissionais que detêm conhecimento sobre o tema.

Se considerarmos o Código de Defesa do Consumidor, que estabelece normas de proteção e defesa do consumidor e define propaganda enganosa e abusiva como aquela que se vale da deficiência de julgamento e experiência da criança e do adolescente, todas as propagandas de produtos deste estudo podem ser consideradas abusi$\mathrm{vas}^{40}$, já que infringem pelo menos três artigos do Regulamento Técnico proposto.

\section{Considerações finais}

Diante dos resultados apresentados que evidenciam os riscos a que as crianças estão expostas, e do potencial de expansão que as indústrias brasileiras apresentam ${ }^{39}$, cabe à sociedade em geral, aos educadores e profissionais de saúde reiterarem a demanda pela propaganda ética e pela pro- 
moção de uma alimentação saudável através da mídia televisiva.

A responsabilidade compartilhada entre sociedade, setor produtivo e setor público é um desafio e o caminho para a construção de modos de vida pautados também nos princípios da pro- moção da saúde e da prevenção de doenças. Sendo assim, as intervenções governamentais que visem proteger a criança de riscos não podem ser entendidas como restrição à liberdade de expressão, mas como instrumentos para a garantia do direito a uma alimentação adequada e saudável.

\section{Colaboradores}

P Henriques foi responsável pela concepção do estudo, interpretou os dados e trabalhou na redação do artigo; EO Sally interpretou os dados e trabalhou na redação do artigo. L Burlandy trabalhou na redação do artigo e na revisão crítica do conteúdo da versão final. RM Beiler coletou e tabulou os dados.

\section{Referências}

1. Garcia RWD. Práticas e comportamento alimentar no meio urbano: um estudo no centro da cidade de São Paulo. Cad Saude Publica 1997; 13(3):455-467.

2. Garcia RWD. Reflexos da globalização na cultura alimentar: considerações sobre mudanças na alimentação urbana. Rev Nutr 2003; 16(4):483-492.

3. Bleil SI. O padrão alimentar ocidental: considerações sobre a mudança de hábitos no Brasil. Rev Cadernos de Debate 1998; 6:1-25.

4. Collaço JHL. Restaurantes de comida rápida, os fast-foods em praças de alimentação de shopping centers: transformações no comer. Estudos Históri$\cos 2004$; 1(33):116-135.

5. Rubim AAC. A contemporaneidade como idade mídia. Interface - Comun Saude Educ 2000; 4(7):25-36.

6. Serra GMA, Santos EM. Saúde e mídia na construção da obesidade e do corpo perfeito. Cien Saude Colet 2003; 8(3):691-701.

7. Sodré M, Moraes D. Entrevista sobre a mídia. Publicação da Pós- Graduação em Comunicação e Cultura 1993; 4:9-25.

8. Souza LCCF. Educação e publicidade. São Paulo Perspec 2000; 14(2):23-31.

9. Ishimoto EY, Nacif MAL. Propaganda e marketing na informação nutricional. Brasil alimentos [periódico na Internet] 2001 [acessado 2009 set 10]; 11:2833. Disponível em: htpp://www.signuseditora. com.br/BA/pdf/11/11\%20-\%20Índice.pdf

10. Pereira RMR. Infância, televisão e publicidade: uma metodologia de pesquisa em construção. Cad Pesqui 2002; 115:235-264.

11. Almeida SS, Nascimento PCBD, Quaioti TCB. Quantidade e qualidade de produtos alimentícios anunciados na televisão brasileira. Rev Saude Publica 2002; 36(3):353-355.

12. Crivelaro LP, Sibinelli EC, Ibarra JA, Silva R. A publicidade na TV e sua influência na obesidade infantil. UNIrevista [periódico na Internet] 2006 [acessado 2008 set 25]; 1(3):1-7. Disponível em: http://www.unirevista.unisinos.br

13. Oliveira AMA, Cerqueira EMM, Souza JS, Oliveira AC. Sobrepeso e obesidade infantil: influência de fatores biológicos e ambientais em Feira de Santana, BA. Arquivos Brasileiros de Endocrinologia \& Metabologia 2003; 47(2):144-150. 
14. Wiecha JL, Peterson KE, Ludwig DS, Kim J, Sobol A, Gortmaker SL. When children eat what they watch: impact of television viewing on dietary intake in youth. Archives of Pediatrics \& Adolescent Medicine 2006; 160(4):436-442.

15. Coon KA, Tucker KL. Television and children's consumption patterns. A review of the literature. Minerva Pediatrics 2002; 54(5):423-436.

16. Engesveen K. Proteção das crianças contra o marketing agressivo de alimentos e bebidas prejudiciais à saúde: $\mathrm{O}$ potencial de uma abordagem baseada nos direitos humanos. Noruega; 2005. [acessado 2009 set 25]. [Documento da Internet]. Disponível em: http:/ /www.abrandh.org.br/artigos/kaiamarketing.pdf

17. Vasconcellos AB, Goulart D, Gentil PC, Oliveira TP. A Saúde Pública e a Regulamentação da publicidade de alimentos. Brasília: Ministério da Saúde (MS). [acessado 2009 out 6]. [Documento da Internet]. Disponível em: htpp://www.nutricao.saude.gov.br

18. Brasil. Consulta Pública $n^{\circ} 71$, de 10 de Novembro de 2006. Proposta de Regulamento Técnico sobre oferta, propaganda, publicidade, informação e a outras práticas correlatas cujo objeto seja a divulgação ou promoção de alimentos com quantidades elevadas de açúcar, de gordura saturada, de gordura trans, de sódio e de bebidas com baixo teor nutricional, quaisquer que sejam as formas e meios de sua veiculação. Diário Oficial da União 2006; 13 nov.

19. Brasil. Ministério da Saúde. Conselho Nacional de Saúde. Resolução CNS no 408, de 11 de dezembro de 2008. Aprova diretrizes para a promoção da alimentação saudável com impacto na reversão da epidemia de obesidade e prevenção das doenças crônicas não transmissíveis. Diário Oficial da União 2009; 09 mar.

20. Instituto Brasileiro de Geografia e Estatística (IBGE). Pesquisa de Orçamentos Familiares 2002-2003: Antropometria e análise do estado nutricional de crianças e adolescentes no Brasil. Rio de Janeiro: Instituto Brasileiro de Geografia e Estatística (IBGE); 2004.

21. Fontenelle IR. O mundo de Ronald McDonald: sobre a marca publicitária e a socialidade midiática. Educ Pesqui 2002; 28(1):137-149.

22. Flick U. Introdução à pesquisa qualitativa. $3^{\text {a }} \mathrm{Ed}$. Porto Alegre: Artmed; 2009.

23. Vala J. A análise de conteúdo. In: Silva AS, Pinto JM, organizadores. Metodologia das Ciências Sociais. Porto: Edições Afrontamento; 1986.

24. Minayo MC. O desafio do Conhecimento: pesquisa qualitativa em Saúde. $4^{\text {a }}$ ed. São Paulo, Rio de Janeiro: Hucitec, Abrasco; 1996.

25. Institute of Medicine (IOM). Dietary reference Intakes for energy, carbohydrate, fiber, fat, fatty acids, cholesterol, protein and amino acids (macronutrients). Washington: National Academy Press; 2005.

26. Halpern G. Comerciais veiculados em programação infanto-juvenil de canais abertos de TV e sua relação com escolha de alimentos [dissertação]. São Paulo (SP): Universidade Federal de São Paulo; 2003.

27. Ruano RI, Pujol MES. Hábitos de vida em una población escolar de Mataró (Barcelona) asociados al número de veces diarias que se ve televisión y al consumo de azúcares. Rev Esp Salud Publica 1977; 1(5):487-498.
28. Anderson DJB, Larson NI, Nelson MC, NeumarkSztainer D, Story M. Does television viewing predict dietary intake five years later in high school students and young adults? Int J Behavioral Nutrition and Physical Activity 2009; 6(7):1-8.

29. Pimenta APAA, Palma A. Perfil epidemiológico da obesidade em crianças: relação entre televisão, atividade física e obesidade. Rev Brasileira de Ciência e Movimento 2001; 9(4):19-24.

30. Santos AM. Sociedade do consumo: criança e propaganda, uma relação que dá peso. [tese]. Porto Alegre (RS): Pontifícia Universidade Católica do Rio Grande do Sul; 2007.

31. Fiates GMR, Amboni RDMC, Teixeira E. Comportamento consumidor, hábitos alimentares e consumo de televisão por escolares de Florianópolis. Rev Nutrição 2008; 21(1):105-114.

32. Brasil. Ministério da Saúde (MS). Secretaria de Atenção à Saúde. Coordenação-Geral da Política de Alimentação e Nutrição. Guia alimentar para a população brasileira: promovendo a alimentação saudável. Ministério da Saúde (MS), Secretaria de Atenção à Saúde, Coordenação-Geral da Política de Alimentação e Nutrição. Brasília: Ministério da Saúde (MS); 2006.

33. Sampaio ISV. Televisão, Publicidade e Infância. 2a ed. São Paulo: Annablume; 2004.

34. Rio de Janeiro. Secretaria Municipal de Saúde. Instituto de Nutrição Annes Dias. Propaganda de Alimentos para crianças e adolescentes. Semana da Alimentação Escolar. Prefeitura do Rio de Janeiro, 2007. [acessado 2008 set 25]. Disponível em: www. saude.rio.gov.br/semana_alimentacao_2007_layout. pdf

35. Story M, French S. Food Advertising and Marketing Directed at Children and Adolescents in the US. Int J Behavioral Nutrition and Physical Activity 2004; 1(3):1-17.

36. Guareschi PA, Romanzini LP, Grassi LB. A "mercadoria” informação: um estudo sobre comerciais de TV e rádio. Paideia 2008; 18(41):567-580.

37. Pinsky I, El Jundi SARJ. O impacto da publicidade de bebidas alcoólicas sobre o consumo entre jovens: revisão da literatura internacional. Rev Bras Psiquiatr 2008; 30(4):362-374.

38. Brasil. Presidência da República. Casa Civil. Lei no 11.346 de 15 de setembro de 2006. Cria o Sistema Nacional de Segurança Alimentar e Nutricional SISAN com vista a assegurar o direito humano á alimentação adequada e dá outras providências. Diário Oficial da União 2006; 18 set.

39. Monteiro CA, Castro IRR. Por que é necessário regulamentar a publicidade de alimentos. Rev Cienc e Cultura 2009; 61(4):56-59.

40. Brasil. Lei $\mathrm{n}^{\circ}$ 8078, de 11 de setembro de 1990. Código de Defesa do Consumidor. Dispõe sobre a Proteção do Consumidor e dá outras Providências. Diário Oficial da União 1990; 12 set.

Artigo apresentado em 15/08/2010

Aprovado em 03/02/2011

Versão final apresentada em 01/03/2011 